\title{
A Comprehensive Dynamic Approach for Selecting the Optimal Position of Telecommunication Towers
}

\author{
${ }^{1}$ Janah Asassafeh, ${ }^{2}$ Murat Akkaya, ${ }^{3}$ Mokhled AlTarawneh \\ ${ }^{1,2}$ Faculty of Business \& Economics, Girne American University, Cyprus \\ ${ }^{3}$ Computer Engineering Dept., Faculty of Engineering, Mutah University, 61710, Jordan
}

\begin{abstract}
The telecommunication industry in Jordan has become highly competitive which adds more pressure on service providers to operate more effectively in the manner of the quality of service without undermining the cost of the service. Selecting the optimal position of the telecommunication tower is one of the most important factors to ensure providing high-quality service at a minimum cost. However, selecting the right position for the tower is complicated and involves different factors such as population density, topology, and reserved area. Unfortunately, the current methods and techniques are not robust enough to ensure selecting the right position effectively, that makes the developing approaches imperative. This paper presents a comprehensive dynamic approach for selecting the optimal position of telecommunication towers; the approach integrates the most common selection factors, rules and the GIS system in a multi-phase process. The accuracy of the proposed approach is relatively high $(82 \%)$, it is evaluated by comparing the recommended positions with the experts' selection.
\end{abstract}

Keywords: Geographic Information System (GIS), Telecommunication Tower Site, Spatial Planning.

\section{INTRODUCTION}

Nowadays, most business industries work under competitive environment where telecommunication is one of them. Selecting better places for a telecomm towers represent one of the main firm's decisions. The better selection has a direct impact on the network cost and covers service area; therefore, the firm budget with competitive services will be enhanced. On the other hand, accelerating selection time and studying the factors affecting the decision and the govern rules are the essence of the solution. The complexity of such decision comes from many criteria's such as: technology restrictions, terrain barriers, climate characteristics, and land properties. The goal of this research is to find a solution techniques for location problems to serve many customers with a fewer facilities [1]. The location problems are divided into two main categories: p-median problems to find the best location facilities among demand area [2], and covering problems, which has two sub set: coverage problems and Maximal Covering Location Problem (MCLP) [3]. Finding a better place for telecomm towers is one of such problem, for that, various techniques and method are available to solve such problems. In this paper we propose a dynamic approach using multi attribute queuing system, applied to Arc-GIS based on best place properties with their weight [4]. We took a real case sample of distributed telecom towers in Jordan and then applied proposed approach using GIS data layers. Candidate points are represented, along with their properties, for the tower location with multi attribute queues. It is based on $\mathrm{T}$ the customer's number, antenna capacity, cell intersection policy, natural barriers, demand area terrine, and received area according to laws and policies. We assume that the current actual locations in the best places.

The remainder of the paper is structured as follows: Section 2 presents the literature review. Section 3 proposes the methodology and approach description. Section 4 discusses the approach implementation. Section 5 explores implementation results. Finally, a research conclusion and future work.

\section{LITERATURE REVIEW}

This section illustrates the literature review for spatial data problem and how were the theories used to reinforce the establishment decision.

\subsection{An Overview of Covering Area Problem}

Since the MCLP was suggested by Church and ReVelle in 1973 [5], many models and methodologies were proposed to achieve MCLP that applied in various sectors to cover area and determine the best location facilities [2]. Such that, [6] used the agglomerative greedy heuristics with genetic algorithms to solve the p-median clustering problem. Moreover, the MCLP was represented as numbering system that has been have ability to represent in computer software [5]. In addition, varying geographic factors and attributes using spatial data and project asset were combined [7]. Moreover, the linear programming relaxation is one of the methods that used to represent respective 0-1 formulations that mostly appropriate for medium-sized problems [8]. To solve 
the differential of land terrain, [7] developed methodology depended on a grid Voronoi diagram that had taken all type of land terrain. In addition, [9] developed polynomial algorithms to solve the coverage problem by using clustering algorithm as a black-box.

For reliable location set [10] suggested mixed integer nonlinear program sought to cover all demand area in continuous states with distributed facilities. The hyper-cube queuing model was proposed by [11] to study the best location of health care resources. [12] Developed a hybrid evolutionary cube. [13] suggest new model using multi-attribute group with multi-facility and objectives, they were used fuzzy set theory and linear programming. Some of the models used GIS, [14] developed solution method that depend on mathematical model using Arc-GIS, heuristic algorithm, and rectangle's grid. [15] Developed a methodology using GIS data with a multiple analytical procedure. [16] Used the Digital Elevation Model with two hierarchy's levels of spatial data by six steps to act the goal: external and internal grid, preprocessing and mining the internal grid. [17] Suggested new method depends on two tools Nonlinear Programming and GIS data.

\subsection{Distributed Wireless Network Models}

Design of distributed nodes is representing the core of the network problem; for that, many methodologies and techniques were suggested. [14] Proposed a new mathematical model for cellular distribution to cover all customers' areas. They take into consideration varying terrain and line-of-sight using Arc-GIS. [16] Studied the better cells distribution of tower sites by retrieving spatial data mining from GIS. They used the digital elevation model to find optimal towers distribution by decreasing their numbers and cover all required area by two hierarchy's levels. [17] Suggested new method to support decision makers in telecomm service to select an optimal mobile switch office sites, for inability problems solution, the capacity current site deal with the increasing number of users and data traffic. Their suggestion depends on two tools Nonlinear Programming and GIS data. [2018] proved that GIS is represent the main tool for supporting selection telecomm tower site decision, [19] suggested simple algorithm for new telecomm tower placement for covering most demand area and serve most customers in lower cost, their algorithm used the satellite image with GIS tool to solve the problem. [20] Used the GIS tool with nonlinear programming method to solve the telecomm base station location problem.

\subsection{Study Area}

Jordan is one of the developing countries in Middle East. Most the area is coverage by $3 \mathrm{G}$ communication services and $4 \mathrm{G}$ internet services [21]. Three main players in industry area
[22]. For differentiation of technology and internal policy the Orange [23] (Jordan Telecom Group) was selected as case of our study. The companies get the spatial data from the Royal Jordanian Geographic Center (RJGC) as the prime original resource of required data in Jordan, and applied this data with Google maps on internal GIS. In addition, telecommunication companies in Jordan must have permission from Telecommunication Regularity Commission- Jordan with the fixed radio frequency and signal strength. Moreover, some requirement conditions must be applied before they start to build any tower [24].

\section{METHODOLOGY}

In order to achieve the aim and objectives of this research to enhance applied management theories that employed the logical methodology and systematic methods of data collection and problem solving. This research employed the result of [25] research which they classified the effective factors on selection telecommunication towers sites, and [4] which classified the effective factors on selection telecommunication towers sites by the companies targets and found the weight of each factors with the procedure to select a conflict. Thus, to be one of the GIS layers for support the decision and to apply a computer system using GIS to find the best tower site, the research will be according to the following steps:

1. Using the results of [25] to build GIS layers (table 4.1 column 2) and [4] as one of the GIS layer to find the effect of each factor on the decision.

2. Linked the research decision effective factors from [4] and [28] results as GIS layers through the Arc-GIS modules , such as population distribution, limitation of technology, signal barriers, land properties, terrain properties, laws and policies barriers.

3. Collect the value of constant variables form the case study company, those factors depend on technology and policy of the company. The output of the survey analysis and constant variables will be the input of linear functions that suggested by [4].

4. Reviewing the process and rules of tower site selection. The interviews with higher-level experts using Delphi method and participant-observation some related companies' documents will be used to find a procedures and models to solve such problem.

5. Dataset representation and collection: the dataset in consistence of the results of [4] and the collected data from different resources (point 3 and 4) will be represented in ArcGIS database. 
ISSN (online): 2581-3048

6. System description and applying: At this point, the procedures, variables, and facts are ready to apply in Arc-GIS. Selected case study will be applied on the Lewae Al-Jamehah that has 158 towers for the Orange Company. The case study area will be divided in 8 folds to test the system behavior. The first iteration will be applied in $12.5 \%$ of the towers' area (13 towers) as explicit towers position to test the system behavior accuracy and it enhancement. The reminder iterations will be applied as implicit towers positions then compare with the actual positions.

7. System results validation: R-squared (R2) measurement was used to validate system output of the explicit data at the first iteration. And then to test the implicit result that come as system output with the actual cases for reminder iterations. The measurement model R2 is one of the most models that using and reporting accuracy measurement of statistical models [24]. Equation 3.1 represents the format of calculation of R2.

$$
R^{2}=\left(\sum_{i=1}^{m}\left(y^{\prime \prime}-y^{\prime}\right)^{2} /\left(\sum_{i=1}^{m}\left(y-y^{\prime}\right)^{2}\right)\right)
$$

Where $\mathrm{m}$ represent the number of the testing selection towers site. $y^{\prime \prime}$ is the system results of the tower sites. $y^{\prime}$ is the actual tower site of the data instance $i$. and $y$ is the mean of actual values.

8. System iterations result validation: The system is validated using k-fold cross-validation method [24]. Equation 3.2 calculated the accuracy of each Kf fold.

$$
a c c f=1 / H \sum_{\sigma\left(v_{i}, y_{i}\right) \in D h} \sigma\left(v_{i}, y_{i}\right)
$$

Where $\sigma(v, y)=1$ if $v=y$ and 0 otherwise. $v i$ is the predicted value of the instance $\boldsymbol{i}, \boldsymbol{y} \boldsymbol{i}$ is the actual value of the instance $\boldsymbol{i}$.

\section{RESULT AND DISCUSSION}

This section includes the findings and results of each step with evaluation method for the accuracy of the proposed system.

\subsection{Data Resources and Dataset Schema}

Beside the data collected from expert opinion and field workers collected in [4] and [24], the proposed system should contain other various data sources to reduce the time and to reach a suitable decision. In this step, we classify data resources which support the approach system, as shown in Table 1.

\begin{tabular}{|c|c|}
\hline Data Source & Data Name \\
\hline \multirow{9}{*}{ RJGC/GIS Layer } & Military Zone \\
\hline & Archeological area \\
\hline & Environmental area \\
\hline & Health services area \\
\hline & Airplanes Routes \\
\hline & Ability to access site \\
\hline & Public Area \\
\hline & Electricity Availability \\
\hline & Interact with electrical Power \\
\hline \multirow{6}{*}{$\begin{array}{l}\text { RJGC / DEM and } \\
\text { Contour Models } \\
\text { Result }\end{array}$} & Flat Area \\
\hline & Steep Terrain \\
\hline & Barriers(Building, Tree) \\
\hline & Slope \\
\hline & Visibility \\
\hline & Higher Area \\
\hline $\begin{array}{l}\text { Department of } \\
\text { Statistics }\end{array}$ & Population users' number \\
\hline \multirow{7}{*}{ Company Data } & Current Towers Placement \\
\hline & Signal strength \\
\hline & Bandwidth \\
\hline & Capacity of Services \\
\hline & Type of Communication System \\
\hline & Signal range ratio \\
\hline & Congestion ratio \\
\hline
\end{tabular}

Table 1: Source of the factors data

The Delphi technique was applied to find the Orange rules for selection tower site. To achieve goal, the questioner was categorized into two parts: coverage area and selection tower position.

\subsubsection{The rules for area segmentation}

1) Starting with the most complex then move to non-visiting adjacent area.

2) Complexity area is divided in four categories:

L1: slop less than $15 \%$ with number of customers more than antenna capacity.

L2: slop less than $15 \%$ with number of customers less $<=$ antenna capacity

L3: customer more the antenna capacity without slop

L4: customer less or equal the antenna capacity 
ISSN (online): 2581-3048

Volume 4, Issue 11, pp 26-34, November-2020 https://doi.org/10.47001/IRJIET/2020.411004

3) For enhancing signal at the end signal area, the intersection policy between coverage cell will be applied depend on Equation 4.1.

Candidate area $=($ coverage area- intersection area $) * 10 \%$

4) For reserved area and non-preferring area (as special case), displacing area shrinking area policy will be applied.

5) To find the effectiveness of the barriers factors on shrinking the signal radius we applied the factors weight in equation 4.2

$$
\mathrm{F}=\mathrm{n}-\sum_{\mathrm{i}=1}^{n} k i
$$

Where $\mathrm{n}$ represents the factor number and $\mathrm{k}$ represents the summation of weight factors.

6) Equation 4.2 is mostly applied to the probability of user's number.

7) The candidate point for the slop area must be cross the each arc less than $120^{\wedge}$ and for the other tower location is preferred to be in the center of coverage circle.

\subsubsection{The rules for selection tower position}

1) Preferring the highest point in the center of each cell.

2) As mentioned before, some areas subjected to special rules such as wider valley (slop less than $15 \%$ ) with small wider (tunnel).

3) Some candidate sites are excluded in reserved or non-preferred area.

4) The best selected position for the tower is the one with maximum radius of antenna signal and that achieved in an area of the free space without barriers. Equation 4.3 shows the method of calculation the radius.

$$
r \max =2 \mathrm{~d} 2 / \lambda
$$

Where $r$ max is the minimum distance from the antenna, $\mathrm{d}$ is the largest dimension of the antenna, and $\lambda$ is the wavelength.

The wavelength $\lambda=c / f$, where $\mathrm{c}$ is the speed of light and $\mathrm{f}$ is the frequency, In our suggested method, the experts prefer to start from the most complex area where the radius of antenna signal is in the smallest case.

5) Land lords are the owners of agreement (acceptance or rejection).
6) Some candidate positions may refuse for erosion problem such as old building, top of the roof or upper steer room.

Table 2 illustrates the constant values that used in Orange.

Referring to P-center problem technique, to find the effectiveness of all factors on each candidate points of cell we apply the equation 4.4 .

$$
W P=\sum_{i=1}^{n} 1-w i
$$

Where 1: represents the candidate point without any barriers. W: represents the barriers weight depending on the weight result in [4].

\begin{tabular}{|l|l|}
\hline Table 2: Orange constant values \\
\hline Slope & $15 \%$ \\
\hline Probability of users increasing & $20 \%$ \\
\hline Frequency range & $400-600 \mathrm{MHz}$ \\
\hline Sight distance and antenna angle & Depend \\
\hline Intersection between cells & $10-25 \%$ \\
\hline
\end{tabular}

\subsection{The Applied Equations and Pseudo Code}

The area that is covered by signal antenna is depending on the wavelength. The maximum radius is covered by signal antenna in free space without barriers and in square angle is given by the equation 4.3 .

Eq. 4.2 represents the relation between number of customers in rush time and the antenna capacity to cover area with complete services. To calculate the effectiveness of the factors to shrink the signal radius we applied the equation 4.3. To calculate the effectiveness of the candidate points' factors we applied the equation 4.4 .

\subsection{System Implementation}

The proposed system was applied on Arc-GIS 10.1 software where all data vectors were uploaded as layers on the system database. Some Arc-GIS 10.1 models were applied to find the necessary results. These models are DEM, contour, and the Arc-Object model.

The Arc-Object model was used to build new models for suggestion the next study areas, to find the candidate towers position by the equations from 4.2 to 4.4 . In the rest of this section, we presented the detail description of system behavior with pseudo code to build the models. Figure 4.1 represents the main steps of building system. 

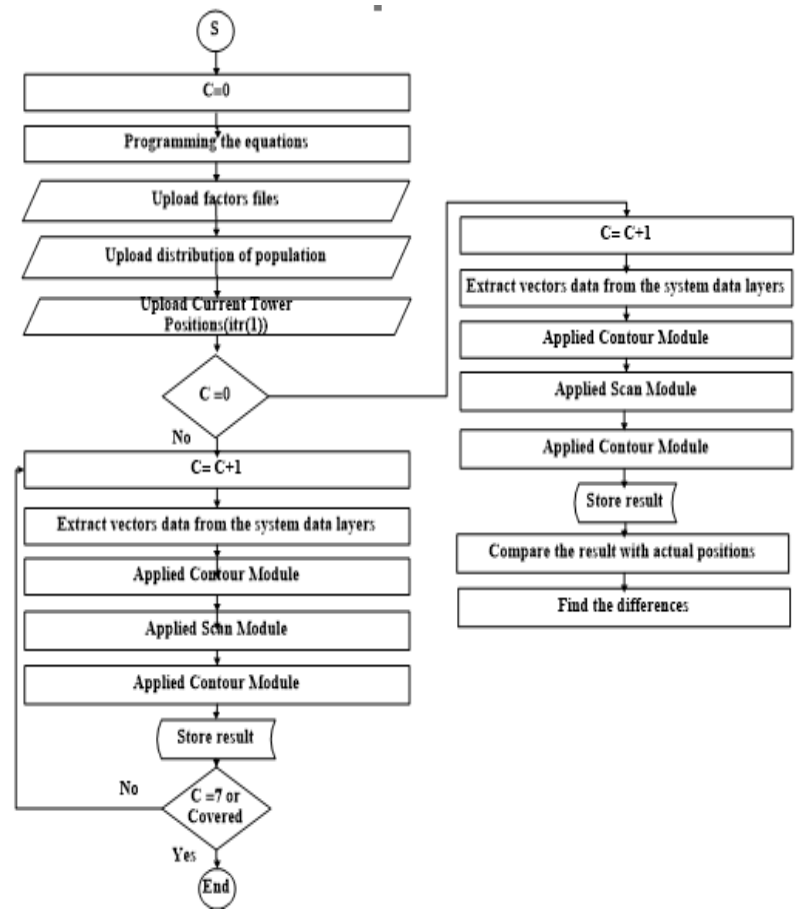

Figure 4.1: The Main Steps of Building system

\subsection{Extract Candidate Towers Positions}

The offering data will be uploaded into Arc-GIS 10.1 to find the best distribution of towers through follow the flowing steps:

Step1: Upload outsources data: figure 4.2represent the geographic data source, in addition the factors name and weights is refer to results [4]. Moreover, constant values and table of reserved area that mentioned in this section are uploaded.

\begin{tabular}{|c|c|c|}
\hline \multirow{2}{*}{$\begin{array}{l}\text { Royal Jordanian Geographic center } \\
\text { (GIS) }\end{array}$} & Reserved area data & \multirow{6}{*}{ System database } \\
\hline & Spatial data properties & \\
\hline \multirow{3}{*}{ The companies' ERP system } & Actual tower distribution & \\
\hline & Towers Elevation & \\
\hline & Covered radius & \\
\hline Department of statistics (GIS) & Distribution of population & \\
\hline
\end{tabular}

Figure 4.2: The source of data vectors

Step 2: Build object modules in Arc-GIS: These modules are used to represent equations and pseudo-code that mentioned in [4].

Step 3: Apply DEM and Contour Module: To find area's height using DEM $20 \mathrm{~m}^{2}$ to create contour map $20 \mathrm{~m}^{2}$. In addition, to find the area slop less than $15 \%$, the Contour Module is applied. Figure 4.3 shows the DEM map, and Figure 4.4 shows the contour map for the target area.

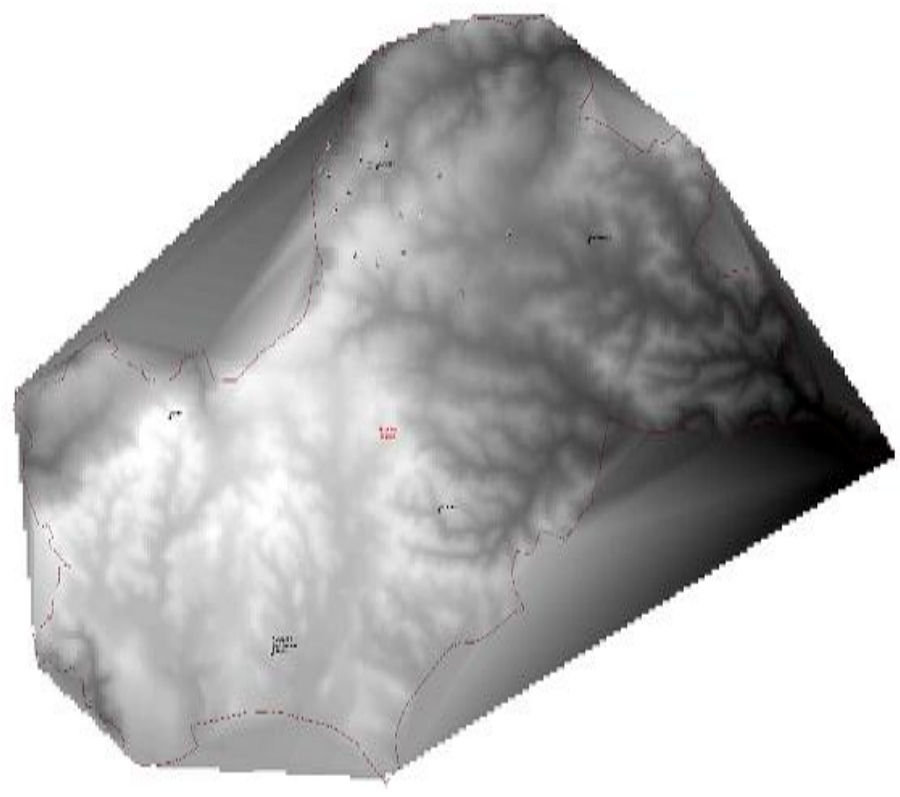

Figure 4.3: DEM map for target area

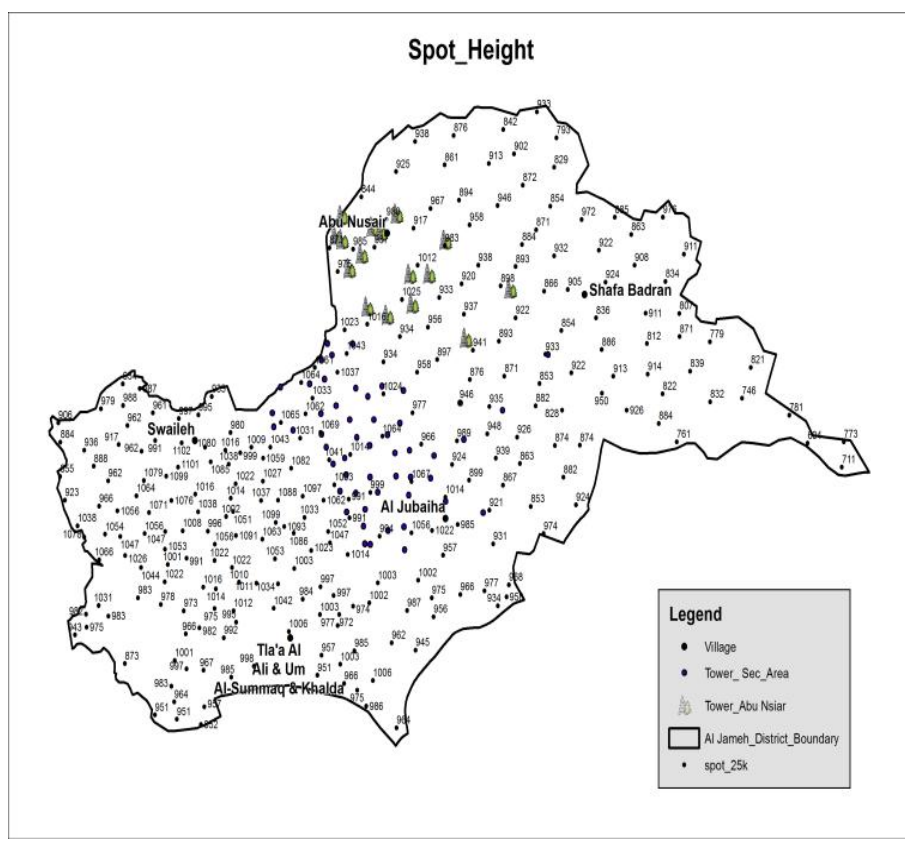

Figure 4.4: Spot height map for target area

Step 4: Apply Scan Module (1): At this stage, all required data is available as vectors in the system database. As result, we can apply the scan module test to find if there any intersection between selection point conditions and using line of sight to test if there is any area was not covered by antenna signal. In addition, to test the explicit tower positions whether they are compatible with conditions (are not in reserved areas or non-preferred areas). We found all the places fulfilled all the conditions. First, for the first iteration and then for complementary. Figure 4.5 show the coverage area with the effective factors and the actual towers positions for the first iteration. 


\section{(彳)}

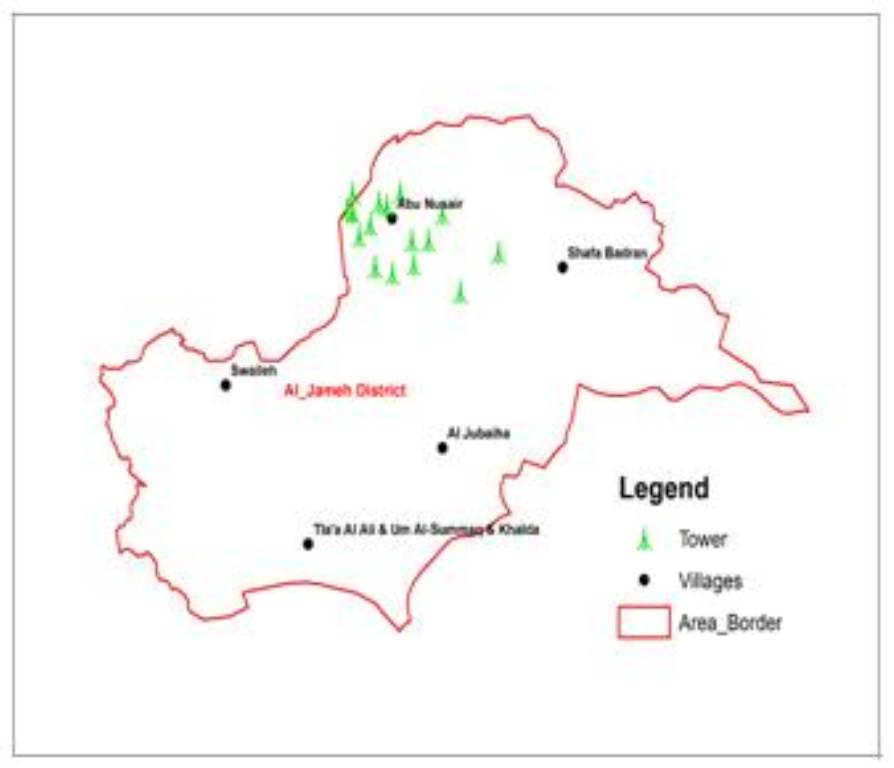

Figure 4.5: Efective factors map on the first iteration

Step 5: Apply Scan Module (2): The aim of this step is to find the area of candidate position for each tower depending on the equation 5.5and then to extract the properties of each site where we request the system to find ten candidate positions for each tower. In addition, to test and ignore points where there any conflict with reserved area and non-preferred area conditions. Table 5.9 has full description of candidate position for each tower for the first iteration.

Step 6: Apply complementary test: For more accuracy of the system, the 7 folds were applied with the same steps. Each iteration has approximately the same area of the first iteration but with different number of towers. In addition, data of actual position of towers is hidden within the iteration was applied. Figure 4.6 show the distribution of towers on contour map and figure 4.7 shows distribution of towers with reserved area for the all case study, and in figure 4.8 the optimal covering area by antenna's towers was appeared.

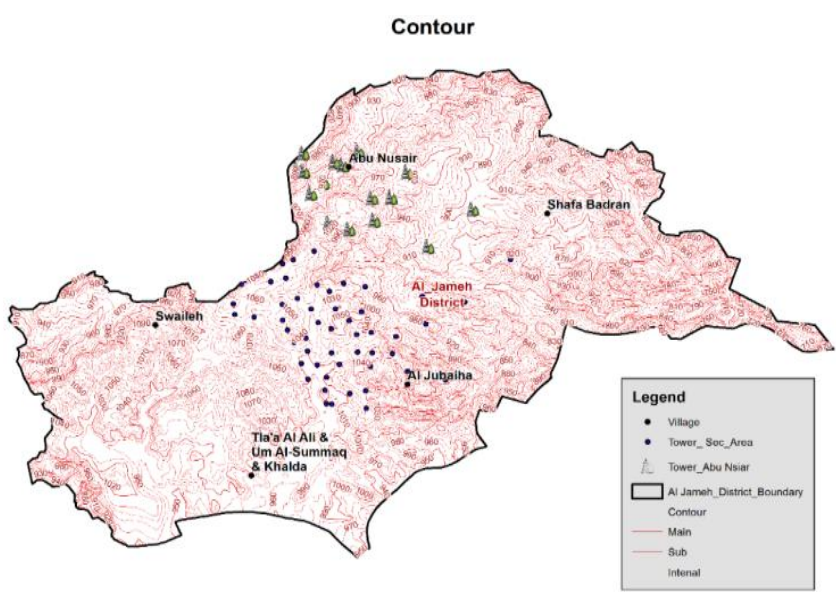

Figure 4.6: Distribution of towers with contour map
ISSN (online): 2581-3048

Volume 4, Issue 11, pp 26-34, November-2020 https://doi.org/10.47001/IRJIET/2020.411004

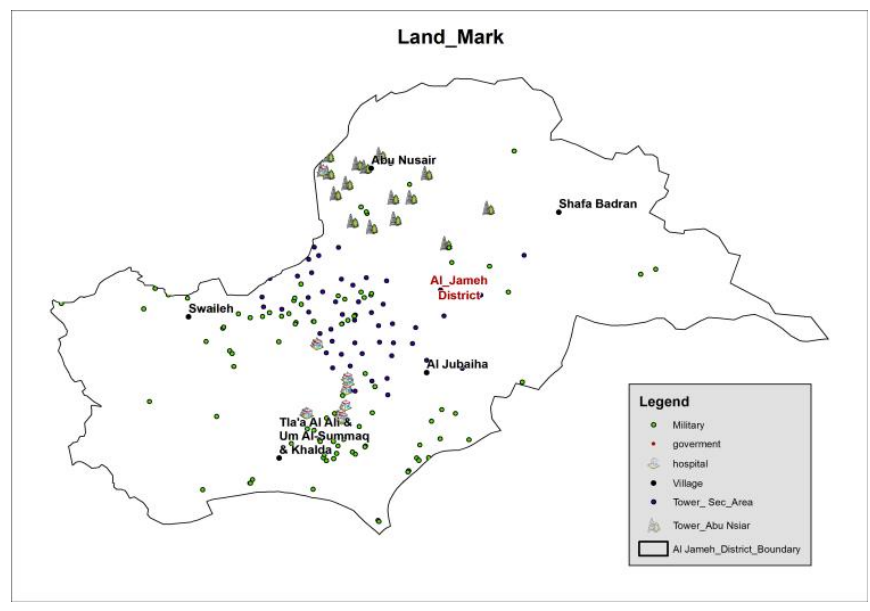

Figure 4.7: Distribution of towers with land used

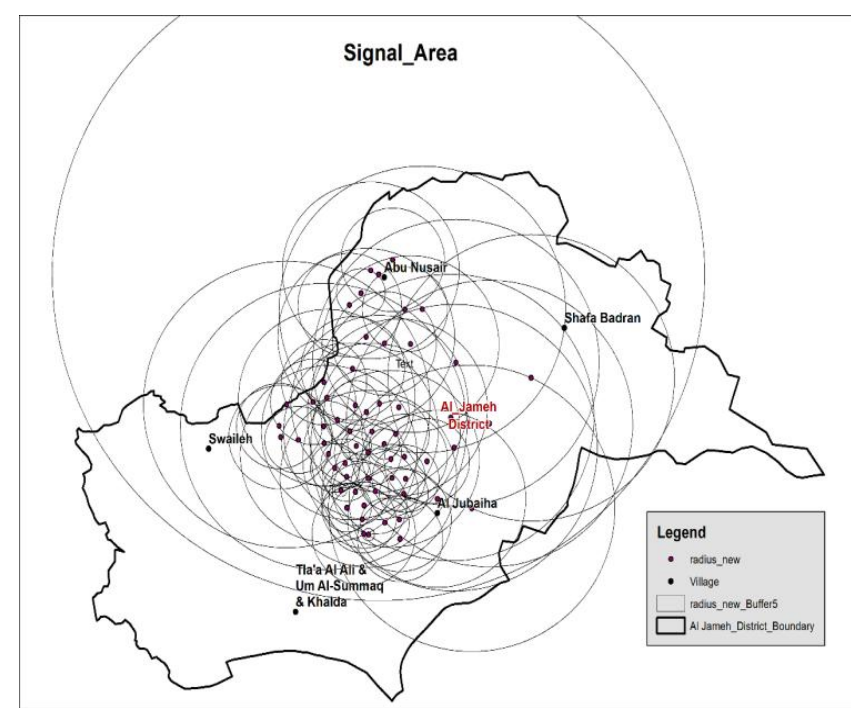

Figure 4.8: Distribution of towers with signal covering area

\section{APPROACH EVALUATION}

\subsection{Precision Analysis}

The evaluation of comparative retrieval accuracy was based on Precision (P). In this comparison a Precision $(\mathrm{P})$ and Real (R) were standard evaluation metrics that used in information retrieval. We use Precision $(\mathrm{P})$ to measure the system ability to present the relevant items where $\mathrm{P}$ defined in equation 5.1 as:

$$
P=R r / A
$$

Where $\mathrm{Rr}$ represent the number of towers that has the same position of the actual position that result calculated by linear function and $\mathrm{A}$ was the number of towers in the iteration.

The evaluation was carried out using the approach retrieval of each sub area depends on the factors value for each candidate position. Table 3 has summarized each approach 
iteration with the actual number of towers and the right and wrong position, in addition the total summation of each of them, at target zero. To validate the result of the approach, we used the R-squared (R2) measurement where (R2) measure is by far one of the most widely used and reported measures of the accuracy of statistical models [22]. R2is formally calculated as shown in Equation 3.1.

Table 3: Accuracy results

\begin{tabular}{|c|c|c|c|c|c|c|c|}
\hline \multirow[b]{2}{*}{$\begin{array}{l}\# \\
\stackrel{\#}{\Xi}\end{array}$} & \multirow[b]{2}{*}{$\begin{array}{l}0 \\
0 \\
0 \\
0 \\
0 \\
0 \\
0\end{array}$} & \multicolumn{2}{|c|}{ current status } & \multicolumn{4}{|c|}{ output system } \\
\hline & & 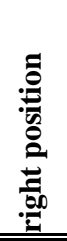 & 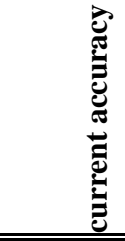 & 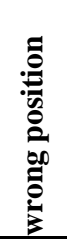 & 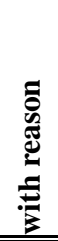 & & 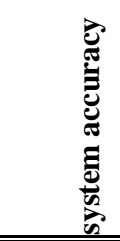 \\
\hline 0 & 13 & 11 & $84.62 \%$ & 3 & 2 & 12 & $92.31 \%$ \\
\hline 1 & 5 & 4 & $80.00 \%$ & 2 & 1 & 4 & $80 \%$ \\
\hline 2 & 4 & 3 & $75.00 \%$ & 1 & 1 & 4 & $100 \%$ \\
\hline 3 & 11 & 7 & $63.64 \%$ & 4 & 0 & 7 & $63.64 \%$ \\
\hline 4 & 8 & 6 & $75.00 \%$ & 2 & 1 & 7 & $87.5 \%$ \\
\hline 5 & 5 & 3 & $60.00 \%$ & 2 & 1 & 4 & $80 \%$ \\
\hline 6 & 8 & 5 & $62.50 \%$ & 3 & 1 & 6 & $75 \%$ \\
\hline 7 & 10 & 8 & $80.00 \%$ & 1 & 0 & 9 & $90 \%$ \\
\hline $\mathrm{T}$ & 64 & 47 & $73.44 \%$ & 18 & 7 & 53 & $82.81 \%$ \\
\hline
\end{tabular}

\subsection{The System validation Using K-Fold}

In this step a $\mathrm{K}$-fold of eight folds $(\mathrm{k}=8)$ were applied. For finding new rules and achieve the high level of accuracy, and so for data approach validation, the first iteration was explicit. The system rule set was applied by holding out the current applied fold (kj). The rule-based system was validated using a k-fold cross-validation [23]. In k-fold cross-validation, the area is divided into $\mathrm{k}$ equal size (of size $\mathrm{h}$ items) subsets called folds; the case study area was partitioned into approximately eight equal sized folds. For moderate Jordan climate, government and company policy, technology, and not available of some data. Moreover, some rules was elicited when applying the first iteration such as building on roof or stair room which affecting the accuracy percentage.

\subsection{Reasoning for Selection Tower Position}

To select the tower position in the target area that comes from Arc-GIS, we used sixteen factors appeared in table 4. The table shows the total effect of these factors on actual and candidate positions. As we noticeable, there are no effects by seven factors. In addition, the total effective on all positions is equal 1713.5 and the effect on the actual position is equal
124.4 equivalents to $7.26 \%$. Mountainous barriers, tower elevation and Slope factors have the highest percentage of effect with $742,306.9$, and 265.6 respectively where they effect on actual towers positions at $(8.22 \%, 4.50 \%$, and $7.76 \%$ ). moreover, some of the tower-elevation-effect were ignored for finding on roof top or on stair room.

Table 4: Total effect of the factors on actual and candidate positions

\begin{tabular}{|l|l|l|l|l|l||}
\hline Factor & \multicolumn{1}{|c|}{ OE } & OAP & OCP & POAP & POCP \\
\hline \hline Barriers & 90 & 9 & 81 & $10 \%$ & $90 \%$ \\
\hline Tree Barriers & 9 & 0 & 9 & $0 \%$ & $100 \%$ \\
\hline Forestry & 43 & 2 & 41 & $4.65 \%$ & $95.35 \%$ \\
\hline Mountainous & 742 & 61 & 681 & $8.22 \%$ & $91.78 \%$ \\
\hline Tower & 306.9 & 13.8 & 293.1 & $4.50 \%$ & $95.50 \%$ \\
\hline Steep Terrain & 198 & 17 & 181 & $8.59 \%$ & $91.41 \%$ \\
\hline Slope & 265.6 & 20.6 & 245 & $7.76 \%$ & $92.24 \%$ \\
\hline Traffic & 44 & 1 & 43 & $2.27 \%$ & $97.73 \%$ \\
\hline Interact with & 15 & 0 & 15 & $0 \%$ & $100 \%$ \\
\hline Airplane Route & 0 & 0 & 0 & $0 \%$ & $0 \%$ \\
\hline Birds & 0 & 0 & 0 & $0 \%$ & $0 \%$ \\
\hline Foliage & 0 & 0 & 0 & $0 \%$ & $0 \%$ \\
\hline Raining & 0 & 0 & 0 & $0 \%$ & $0 \%$ \\
\hline Wind Loading & 0 & 0 & 0 & $0 \%$ & $0 \%$ \\
\hline Lightning and & 0 & 0 & 0 & $0 \%$ & $0 \%$ \\
\hline Interact with & 0 & 0 & 0 & $0 \%$ & $0 \%$ \\
\hline Total & 1713.5 & 124.4 & 1589.1 & $7.26 \%$ & $92.74 \%$ \\
\hline \hline
\end{tabular}

\section{CONCLUSION AND FUTURE WORK}

The researchers has presented a new system approach to support a decision making in selection telecommunication towers sites in planning stage. We employed the results of [4, 24] as the input of the system approach to act the research goals. The rules of selection towers site were studied through open-end questioners with the companies' experts, where some of them from the case study company Orange. Moreover, the constant values were derived directly from the Orange documents. In addition, the current towers' places for the area case study were gotten from Orange GIS. All of these represent the system dataset with coding the equations and pseudo code that appeared in [4]. The proposed approach was applied in Arc-GIS 10.1 by cooperation with RJGC using DEM, contour models and object models. The proposed approach was executed in eight iterations where the first one has the explicit towers site to test the rules and dataset, the reminders was executed with implicit data where the system suggested the towers places. The result was validated using, the R2 method. The result of comparison showed an $82 \%$ accuracy performance. However, the result accuracy may improve by used more limitation of data layers, in addition, by 
ISSN (online): 2581-3048

Volume 4, Issue 11, pp 26-34, November-2020 https://doi.org/10.47001/IRJIET/2020.411004

finding new layers for buildings that unbearable towers weights and full database for the landlords.

\section{REFERENCES}

[1] A. Konak, S. Kulturel-Konak, and L. Snyder, "A MultiObjective Approach to the Competitive Facility Location Problem," Procedia Computer Science, vol. 108, pp. 14341442, 2017.

[2] M. Karatas, N. Razi, and H. Tozan, "A Comparison of pmedian and Maximal Coverage Location Models with Qcoverage Requirement," Procedia Engineering, vol. 149, pp. 169-176, 2016.

[3] R. Z. Farahani, N. Asgari, N. Heidari, M. Hosseininia, and M. Goh, "Covering problems in facility location: A review," Computers and Industrial Engineering vol. 62, no. 1, pp. 368407, 2012.

[4] J. A. Asassfeh, M. S. AlTarawneh, and F. Samson, "Integrative Model for Quantitative Evaluation of Selection Telecommunication Tower Site," Telkomnika, vol. 16, no. 3, pp. 1158-1164, 2018.

[5] Murray, Alan T. "Maximal coverage location problem: impacts, significance, and evolution." International Regional Science Review 39.1 (2016): 5-27.

[6] Kazakovtsev, L. A., A. N. Antamoshkin, and V. V. Fedosov. "Greedy heuristic algorithm for solving series of EEE components classification problems." IOP conference series: materials science and engineering. Vol. 122. No. 012011. 2016.

[7] A. T. Murray, T. C. Matisziw, D. Tong, and H. Wei, "Geo Computational approaches to coverage maximization in service facility siting," in Geo Computation Kildare, Ireland, 2007.

[8] D. Ozgen and B. \&Gulsun, "Combining possibilistic linear programming and fuzzy AHP for solving the multi-objective capacitated multi-facility location problem," Information Sciences, vol. 268, pp. 185-201, 2014.

[9] Jones, Matthew, Huy Lê Nguyen, and Thy Nguyen. "Differentially Private Clustering via Maximum Coverage." arXiv preprint arXiv:2008.12388 (2020).

[10] R. Blanquero, E. Carrizosa, and B. G.-Tóth, "Maximal Covering Location Problems on networks with regional demand," Omega, Elsevier, vol. 64, no. C, pp. 77-85, 2016.

[11] S. Belciug and F. Gorunescu, "Improving hospital bed occupancy and resource utilization through queuing modeling and evolutionary computation," Journal of biomedical informatics, vol. 53, pp. 261-269, 2015.

[12] A. Rahmani and S. A. MirHassani, "A hybrid FireflyGenetic Algorithm for the capacitated facility location problem," Inf. Sci., vol. 283, pp. 70-78, 2014.

[13] C. Kahraman, D. Ruan, and I. Doğan, "Fuzzy group decision-making for facility location selection," Information sciences, vol. 57, pp. 135-153, 2003.

[14] J. K. Deane, T. R. Rakes, and L. P. Rees, "Efficient heuristics for wireless network tower placement," Information Technology and Management, vol. 10, no. 1, pp. 55-65, 2009/03/01 2009.

[15] C. Domenikiotis, N. R. Dalezios, and I. Faraslis, "GISbased weather radar siting procedure in mountainous terrain," Physics and Chemistry of the Earth, Parts $A / B / C$, vol. 35, no. 1, pp. 35-42, 2010.

[16] A. H. AL-Hamami and S. H. Hashem, "Optimal Cell Towers Distribution by using Spatial Mining and Geographic Information System," World of Computer Science and Information Technology Journal (WCSIT), vol. 1, no. 2, pp. 44-48, 2011.

[17] J. Y. Oh, J. Yu, and R. A. Aukerman, "Decision making tools in cellular telecommunication network design: GIS and NIP," Issues Inf Syst, vol. 8, no. 2, pp. 97-102, 2007.

[18] R. Kashyap, M. S. Bhuvan, S. Chamarti, P. Bhat, M. Jothish, and K. Annappa, "Algorithmic Approach for Strategic Cell Tower Placement," presented at the Fifth International Conference on Intelligent Systems, Modelling and Simulation, 2014.

[19] S. A. Karulkar, " Optimal allocation of cell towers for cellular network expansion " $\mathrm{PhD}$, Texas A\&M UniversityKingsville, 2016.

[20] "E-government report, "JORDAN NATIONAL INFORMATION AND COMMUNICATIONS TECHNOLOGY STRATEGY (2013-2017) report"," 2012. [Online]. Available:

[21] "Telecommunications Regulatory Commission,"“Jordan regulates rules and polices"." http://www.trc.gov.jo/ accessed.

[22] O. group, "Orange annually report," 2015. [Online]. Available:

https://www.orange.jo/en/documents/annual_report/orange_an nual_report_2015_en.pdf 
ISSN (online): 2581-3048

Volume 4, Issue 11, pp 26-34, November-2020

https://doi.org/10.47001/IRJIET/2020.411004

[23] J. A. Asassfeh, F. Samson, and M. S. AlTarawneh, "Reviewing and Classifying the Effective Factors in Selection Telecommunication Antenna Towers Sites," International Journal of Digital Information and Wireless Communications, vol. 7, no. 3, pp. 178-184, 2017.
[24] J. Mandel, The statistical analysis of experimental data. Courier Corporation, 2012.

[25] S. Arlot and A. Celisse, "A Survey of Cross-Validation Procedures for Model Selection," Statistics Surveys, vol. 4, pp. 40-79, 2010.

\section{Citation of this Article:}

Janah Asassafeh, Murat Akkaya, Mokhled AlTarawneh, “A Comprehensive Dynamic Approach for Selecting the Optimal Position of Telecommunication Towers" Published in International Research Journal of Innovations in Engineering and Technology - IRJIET, Volume 4, Issue 11, pp 26-34, November 2020. https://doi.org/10.47001/IRJIET/2020.411004 